\title{
Special volume on mathematical modeling with applications
}

\section{Froilan Dopico ${ }^{1} \cdot$ Khalide Jbilou $^{2} \cdot$ Mohammed Seaid $^{3}$}

Received: 11 June 2020 / Accepted: 15 June 2020 / Published online: 1 July 2020

(C) Springer Science+Business Media, LLC, part of Springer Nature 2020

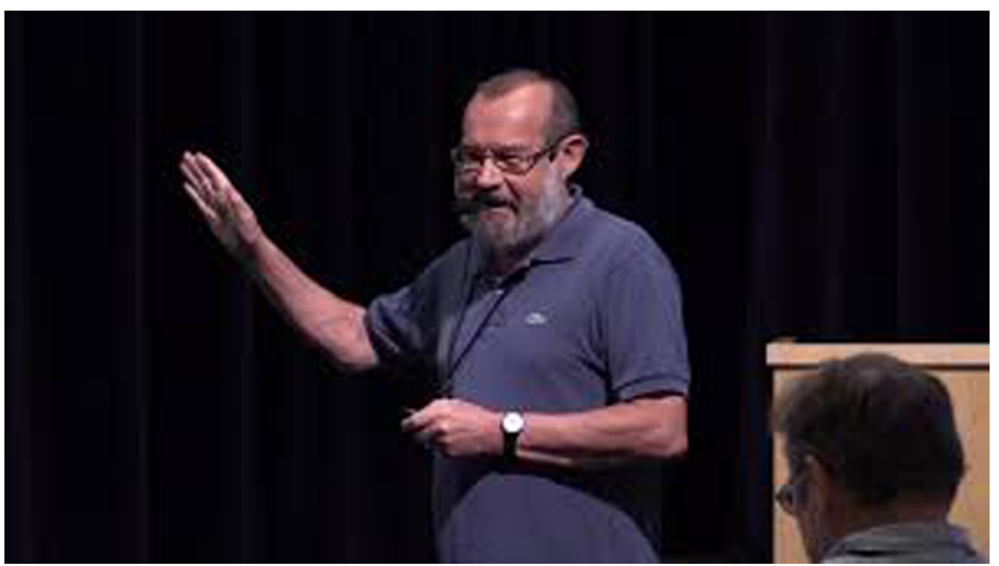

This special volume of Numerical Algorithms is dedicated to the conference Mathematical Modeling with Applications (M2A19) held at Mohamed V University in Rabat, Morocco, on April 1-4, 2019. This event was co-organized by University Littoral Côte d'Opale in Calais France and Mohamed V University and the main organizers of the conference are S. El Bernoussi, K. Jbilou, and A. Messaoudi.

The aim of the conference was to bring together researchers working in numerical linear algebra and mathematical modeling and applications. It was attended by more than 120 participants and 10 plenary and invited speakers, from academia and research laboratories. The main topics of the conference were:

Dedicated to Gérard Meurant on the occasion of his 70th birthday

Khalide Jbilou

Khalide.Jbilou@univ-littoral.fr

1 Universidad Carlos III de Madrid, Departamento de Matematicas, Madrid, Spain

2 Université du Littoral Cote D’Opale, Calais, France

3 Durham University, Department of Engineering, Durham, United Kingdom 
- Numerical Linear Algebra with Applications,

- Matrix Computation,

- Approximation, Optimization,

- Inverse and ill-posed problems-Image processing,

- Numerical Methods for PDEs,

- Computational Statistics.

The conference was dedicated to Gérard Meurant for his many highly influential contributions to numerical linear algebra.

This Special Issue contains accepted papers for publication after a refereeing process that meets the standards of the journal Numerical Algorithms.

The Guest Editors would like to thank Professor Claude Brezinski, the Editor in chief of Numerical Algorithms for his support, and encouragement.

We express our gratitude to all participants for their contributions and for making the congress an interesting and pleasant event. We also thank the authors of the selected papers and the referees for their valuable work and recommendations.

Special volume editors

Froilan Dopico, Spain (Guest Editor)

Khalide Jbilou, France (Managing Guest Editor)

Mohamed Seaid, (Guest Editor)

Publisher's note Springer Nature remains neutral with regard to jurisdictional claims in published maps and institutional affiliations. 